Departamento de Química Orgânica e Biológica Diretor: Prof. Dr. Fonseca Ribeiro

\title{
VITAMINA C CONTIDA NA LARAN]A BAÍA, CITRUS SIMENSIS L.
}

\section{José Danilo Pecci e O. F. Ribeiro}

E' fora de duvida que os frutos citricos representam uma das principais fontes de suprimento da vitamina $\mathrm{C}$, na dieta da maioria dos povos, maximé nos países de clima quente. A importância do limão, neste particular, é tradicional muito embora as caracteristicas de palatabilidade do fruto sejam um obice ao seu consumo em quantidades grandes. Dentre as variedades de laranja cada região elege, via de regra, algumas que são consumidas em maior escala porem dentre todas a que assume no Brasil mais importância é a variedade Baía, já porque é muito grande a sua preferência no mercado interno, já porque representa o tipo escolhido para exportação.

Nas pesquizas de PaUla Souza e colaboradores (1) é referido o resultado de $54 \mathrm{mg}$. de vitamina $\mathrm{C}$ por $100 \mathrm{gr}$. de caldo da laranja Baía porem o método empregado para a dosagem foi o da titulação direta pelo 2,6-diclorofenolindofenol, sem valoração do ácido dehidroascórbico capaz de reduzir-se à vitamina $\mathrm{C}$, e sem determinação de eventuais substancias interferentes, Tillmans-redutoras, que podem falsear os resultados.

\section{PARTE EXPERIMENTAL}

Nas dosagens que realisamos visando estabelecer um valor medio para o teôr em vitamina $\mathrm{C}$, da laranja Baía, valemo-nos do metodo especifico da ascorbinase, segundo RIBEIRo, BoNoLDI e RIBEIRo (2). Realisamos as dosagens em amostras da fruta bem madura e em amostras mais verdes, já em condições, entretanto, de consumo. Por outro lado, atendendo a que, frequentemente a laranja é consumida sob forma de refrescos (caldo de laranja), procuramos indagar se nestas condições haveria perda de vitamina $\mathrm{C}$ num espaço de tempo razoável (até 24 horas) e em temperatura ambiente. 
Eis os resultados:

TEÔR EM VITAMINA C DA LARANJA BAfA

\begin{tabular}{|c|c|c|c|c|c|c|c|}
\hline \multicolumn{6}{|c|}{ Amostras } & $\begin{array}{l}\text { Fruto bem maduro } \\
\text { mgr. por } 100 \mathrm{gr} \text {. } \\
\text { de caldo }\end{array}$ & $\begin{array}{c}\text { Fruto menos maduro } \\
\text { mgr. por } 100 \mathrm{gr} \text {. } \\
\text { de caldo }\end{array}$ \\
\hline 1 & & . & . & . & . & 73,6 & 87,0 \\
\hline 2 & . & . & . & . & . & 66,0 & 94,0 \\
\hline 3 & . & . & . & . & . & 64,5 & 105,5 \\
\hline 4 & . & . & . & . & . & 62,9 & 96,7 \\
\hline 5 & . & . & . & . & . & 69,9 & 69,2 \\
\hline 6 & . & . & . & . & . & 60,5 & 80,0 \\
\hline 7 & . & . & . & . & . & 43,5 & 88,6 \\
\hline 8 & . & . & . & . & . & 57,3 & 58,6 \\
\hline 9 & . & . & . & . & . & 63,5 & 82,8 \\
\hline 10 & . & . & . & . & . & 75,0 & 103,3 \\
\hline 11 & . & . & . & . & . & 62,5 & 58,9 \\
\hline 12 & . & . & . & . & . & 54,5 & 66,5 \\
\hline 13 & . & . & . & . & . & 57,5 & 48,7 \\
\hline 14 & . & . & . & . & . & 63,6 & 59,3 \\
\hline 15 & . & . & . & . & . & 63,8 & 70,3 \\
\hline 16 & . & . & . & . & . & 59,0 & 61,3 \\
\hline 17 & . & . & . & . & . & 53,8 & 67,7 \\
\hline 18 & . & . & . & . & . & 55,9 & 67,4 \\
\hline 19 & . & . & . & . & . & 68,9 & 56,9 \\
\hline 20 & . & . & . & . & . & 55,3 & 67,4 \\
\hline 21 & . & . & . & . & . & 66,2 & 112,9 \\
\hline 22 & & . & . & . & . & 49,9 & 105,1 \\
\hline 23 & . & . & . & . & . & 55,9 & 111,7 \\
\hline 24 & . & . & . & . & . & 78,7 & 134,1 \\
\hline 25 & . & . & . & . & . & 58,1 & 106,4 \\
\hline 26 & & . & . & . & . & 62,5 & 116,4 \\
\hline 27 & & . & . & . & . & 60,9 & 106,8 \\
\hline 28 & & . & . & . & . & 62,7 & 114,7 \\
\hline 29 & & . & . & . & . & 56,8 & 77,6 \\
\hline \multirow[t]{4}{*}{30} & & & . & . & . & 79,3 & 94,5 \\
\hline & & & & & & $\mathbf{M}=62,2$ & $M=85,6$ \\
\hline & & & & & & $\sigma=7,9$ & $\sigma=22,0$ \\
\hline & & & & & & $\mathrm{v}=12,7 \%$ & $\mathrm{v}=25,7 \%$ \\
\hline
\end{tabular}

Existe, evidentemente uma diferença no conteúdo em vitamina C a favor dos frutos menos maduros. Convem referir que parece existir tambem uma certa importância no tamanho da fruta uma vez que os resultados mais elevados nós os encontramos quasi sempre em amostras de menor tamanho. Acenamos apenas para o fato visto que não era nossa preocupação verificar esse detalhe. 
No caldo de laranja deixado em temperatura ambiente os resultados que obtivemos foram os que seguem:

TEÔR EM VITAMINA C (do caldo de laranja deixado em temperatura ambiente)

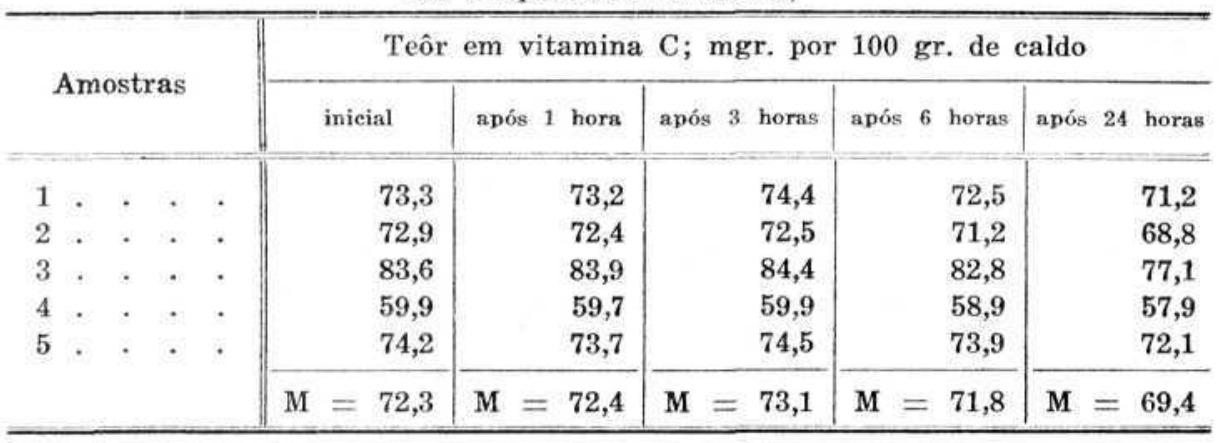

Verifica-se, por este quadro que a conservação do acido ascórbico no caldo de laranja Baía se faz perfeitamente bem e que mesmo após 24 horas a perda não foi significativa, colocando-se nas proximidades de apenas $4 \%$. Tal fato representa uma garantia de aproveitamento da vitamina $\mathrm{C}$ sob forma de refrescos de laranja.

\section{RESUMO}

A dosagem da vitamina C na laranja Baía (Citrus simensis, L.) feita pelo metodo especifico da ascorbinase revelou os seguintes valores:

fruta bem madura:

$$
\begin{aligned}
\mathrm{M} & =62,2 \mathrm{mgr} . \text { por } 100,0 \mathrm{gr} \text {. de caldo } \\
\sigma & =7,9 \\
\mathrm{v} & =12,7 \%
\end{aligned}
$$

fruta menos madura:

$$
\begin{aligned}
\mathrm{M} & =85,6 \mathrm{mgr} . \text { por } 100,0 \mathrm{gr} . \text { de caldo } \\
\sigma & =22,0 \\
\mathrm{v} & =25,7 \%
\end{aligned}
$$

O caldo de laranja destinado ao consumo sob forma de refresco, mesmo mantido em temperatura ambiente, não acusou perda apreciável durante 24 horas.

\section{BIBLIOGRAFIA}

(1) Paula Souza, G. H., A. Wancolle, M. Mesquita, Fonseca Ribeiro e P. E. Carvalho - 1936 - Rev. Bras. Chim. 1 (5): 193-201.

(2) Ribeiro, Renato F., V. Bonoldi e O. F. Ribeiro - 1942 - Rev. Fac. Med. Vet. S. Paulo 2 (2) : 29-39. 